\title{
Molecular and Cellular Mechanisms of Genito-Urinal Menopausal Syndrome and Pathogenetic Methods of Its Correction
}

\author{
Kvetnoy IM ${ }^{1,2}$, Toktar $\mathrm{LR}^{3}$, Orazov $\mathrm{MR}^{3}$, Polyakova V0 ${ }^{1,4}$, Drobintseva $\mathrm{A0}^{1,4}$, Tsypurdeeva $\mathrm{A} \mathrm{A}^{1}$ \\ ${ }^{1}$ Department of Gynecology and Reproductology, Federal State Budgetary Institution Ott Research Institute of Obstetrics, Russia \\ ${ }^{2}$ Department of Pathology, Saint-Petersburg State University, Russia \\ ${ }^{3}$ Department of Obstetrics and Gynecology with Perinatology Course of the Medical Institute of the Russian Peoples 'Friendship University, Russia \\ ${ }^{4}$ FSBEI HE Saint Petersburg State Pediatric Medical University MoH Russia
}

Submission: April 23, 2020; Published: May 04, 2020

*Corresponding author: Orazov Mekan Rakhimberdyevich, Department of Obstetrics and Gynecology with Perinatology Course of the Medical Institute of the Russian Peoples ' Friendship University, Russia

\section{Abstract}

Proliferative activity of the vaginal epithelial cells is reduced with a deficiency of sex steroids due to menopause. The article deals with the molecular-cellular mechanisms of aging of vaginal epithelial cells in genitourinary menopausal syndrome (GUMS), as well as immunocytochemical effects of hormone-containing drugs used for topical therapy of GUMS.

Methods: The effect of 4 drugs on in vitro aging of vaginal epithelial cell culture was studied: monotherapy with estriol 0.5 mg, monotherapy with micronized progesterone $100 \mathrm{mg}$, complex preparations of estriol $0.03 \mathrm{mg}$ with lyophilized acidophilic lactobacilli and estriol $0.2 \mathrm{mg}$ with micronized progesterone $2 \mathrm{mg}$ and lyophilized culture of viable lactobacilli L. casei rhamnosus Doderleini. The immunocytochemical response of 5 markers associated with cellular aging was studied: ER, PR, Ki-67, TNF $\alpha$, IL-1RA.

Results: it was revealed that ET on vaginal cells inhibits the expression in their nuclei of both ER and PR. It is established that PT conditions for estrogenization of vaginal cells, and hence the glycogen synthesis. For the formation of ER, only progesterone exposure is not enough, low $\mathrm{pH}$ level is necessary. Acidic environment provided by Lactobacillus promotes expression of PR, and also affects the reduction of expression of cellular aging markers TNF $\alpha$ and IL-1RA.

Conclusion: Pathogenetically justified therapy of GUMS is not only therapy with estriol, but a combination therapy with progesterone and lactobacilli. It was EPT with lactobacilli L. casei rhamnosus Doderleini that showed a statistically significant increase in the expression of ER and $\mathrm{PR}$, significant decrease in the marker of cellular aging TNF $\alpha$.

Keywords: Genitourinary menopausal syndrome; vulvo-vaginal atrophy; biocoenosis; estriol, progesterone

\section{Introduction}

The problem of menopausal disorders is particularly acute in modern society, characterized by a general aging of the population. Every fifth citizen of Russia is over 60 years old, and the average life expectancy of women is 76.2 years. For women, the overall increase in life expectancy has a reverse side, this reverse exists for them because the female body, created by nature with the obligatory estrogenic influence, is forced to spend about a third of the entire life expectancy without this support. Such a long period of time, with typical hot flashes, sweating, insomnia, depressive disorders, dysuria, dyspareunia, osteoporosis and other manifestations of the natural extinction of ovarian function is often impossible to live without medical care $[1,2]$. But if vasomotor and psychoemotional symptoms, even with their medium severity, tend to decrease over time, urogenital disorders over time not only do not disappear, but even become more intense. Lack of estrogenization of tissues, which occurs in peri - and post menopause, leads to atrophic processes of the vaginal walls, which lose their elasticity, the folding of the mucous membrane disappears, it becomes smooth, dry and shiny. The functional layer of the vaginal mucosa gradually disappears, the 
formation of glycogen decreases, the vaginal biotope is disturbed and the production of lactic acid decreases, and the reaction of the vaginal secretion becomes neutral or alkaline [3]. Thus, age-related suppression of cell proliferation occurs through immunoendocrine mechanisms. At the biochemical level, several links are known to affect tissue aging, including Estrogen (ER) and progesterone (PR) receptors, Ki-67 protein, tumor necrosis factor $(\mathrm{TNF} \alpha)$, and interleukin-1 receptor antagonist (IL-1RA). Estrogen (ER) and progesterone (PR) receptors. Estrogens, affecting target tissues, including the vaginal wall, work not only as a unique proliferative agent, but contribute to the secretory transformation of cells. This multifaceted effect is due to the fact that estrogens stimulate the synthesis of not only their own receptors, but also progesterone and androgen receptors. And progesterone, on the contrary, inhibits the synthesis of both own and estrogen receptors. Thus, a full hormonal effect in the target tissues can be achieved only under the condition of a balanced ratio and dynamics of the aggregate concentrations of the main female sex steroids in the aggregate. Estrogens perceive several types of receptors at the same time, the main ones are alpha and beta (hereinafter ER- $\alpha$ and ER- $\beta$ ). It has been shown that the function of ER- $\alpha$ and ER- $\beta$ differs slightly in the epithelium of target organs: the first play a dominant role in cell proliferation, and the second-in their secretory activity $[1,2]$. Interestingly, progesterone, suppressing the expression of ER- $\alpha$, stimulates the synthesis of ER- $\beta$.

Progesterone as a steroid hormone has nuclear receptors consisting of a heterooligomeric protein complex (holoreceptor). The mechanism of action of holoreceptors is to increase the affinity of the protein to nuclear chromatin, resulting in a heat shock protein with a molecular weight of $90 \mathrm{kDa}$ (HSP-90) [4]. The complex of hormone and receptor is translocated from the cytoplasm into the nucleus, accumulating in chromatin and modulating the transcription process, and then breaks down. Activation of progesterone Receptors (PR) leads to the expression of genes associated with tissue growth, increased levels of auxiliary proteins of the transforming growth factor beta (TGF- $\beta$ ) and Epidermal Growth Factor (EGF). In particular, it is known that the expression of PR increases significantly in the presence of tumor growth, which indicates the association of this protein with the cell cycle and, consequently, aging processes $[5,6]$. Since estrogens and progesterone realize proliferative and secretory functions through receptors, their study is an important task in the study of the aging process [7].

Cell proliferation marker (Ki-67). Ki-67 is an important marker of cell proliferation, which is involved not only in the development of tumor processes, but also in the aging processes. Currently, Ki-67 is actively used as a predictive indicator to assess cell proliferation in biopsy material taken from cancer patients [8, 9]. The involvement of Ki-67 in aging processes was investigated by Grigoryan V Yu [10], who showed a significant decrease in the level of this marker with age and disturbance of hormonedependent tissue proliferation on the example of endometrial cell cultures. Ki-67 is a nuclear DNA-binding protein represented in humans by two isoforms with molecular weights of $320 \mathrm{kDa}$ and $359 \mathrm{kDa}$ [11]. Protein levels and localization vary depending on the cell cycle, and maximum expression is found in the G2 phase or during mitosis. In interphase, Ki-67 forms fibrous structures in the regions surrounding nucleoli near satellite DNA (that is, in the telomeric and centromeric regions of chromosomes) as part of protein complexes binding to them. Ki-67 is a direct substrate of cyclin-dependent kinase CDK1, hyper phosphorylating during mitosis $[11,12]$.

Tumor necrosis factor (TNF- $\alpha$ ). Other important substances for the process of cellular aging are cytokines of specific transmembrane proteins of the TNF family, or tumor necrosis factor. They implement the receptor-dependent pathway of apoptosis and therefore have a proinflammatory effect, actively produced in rheumatic diseases, infections and malignancies. The prototype for a number of substances belonging to the above family is TNF- $\alpha$. At the microorganism level TNF- $\alpha$ promotes the development of hyperthermia, increased catabolism, hypercoagulation, hypotension, increased adhesion of cells to each other. Studies performed by F. Riche (1996) became controversial as they showed paradoxical anti-inflammatory effect of TNF- $\alpha$ in sepsis $[13,14]$. This cytokine, as an angiogenic factor, stimulates the proliferation of endothelial cells and increases vascular permeability $[15,16]$. Thus, TNF- $\alpha$ is a multifunctional proinflammatory cytokine that can perform both anti-inflammatory action and act as a marker of various diseases associated with cell proliferation. Antagonist of the interleukin-1 receptor (IL-1RA). Interleukin-1 (IL-1) is a mediator of acute and chronic inflammation, a cytokine produced by immunocompetent cells (macrophages, keratinocytes, fibroblasts). Expression of the IL-1 gene begins only after activation of cells by inducers. A wide variety of substances can act as inducers, the main of which are components of the bacterial cell wall - lipopolysaccharides, peptidoglycans, muramyldipeptide, etc., but also other cytokines (IL-2, IL-6, TNF- $\alpha$, etc.), as well as a number of chemical compounds (polymyxin B dextran sulfate) and even latex [17]. The biological activity of IL-1 is realized through specific receptors on target cells. These receptors are represented by the extracellular part containing three immunoglobulin-like domains, and the socalled cytoplasmic tail. It is important that after binding of IL-1 to extracellular domains of receptors the whole biochemical cascade with participation of serine protein kinase is launched, as a result of which the activating signal is transferred inside the cell. It is this signaling pathway that blocks the IL-1RA protein, thus being a natural inhibitor of the biological (pro-inflammatory) effects of IL-1. This occurs even if the cytokine is produced in a sufficiently large amount and the proinflammatory cascade is over-activated [18]. Thus, the IL-1 receptor antagonist has an anti-inflammatory effect and even its synthetic analogue called anakinra is used in the therapy of rheumatic diseases. It is known that IL-1 has two varieties - alpha and beta, and that humans predominantly produce the $\beta$-form, whereas the $\alpha$-form is thought 
to be murine. Interestingly, the structure of the IL-1RA molecule, its protein sequence, is closer to the $\beta$-form of interleukin-1 [19]. Another important fact is not only the anti-inflammatory effect of IL-1RA, but also the induction of cellular aging, and it is in this role that it is important to study the participation of cytokines in the pathogenesis of tissue changes associated with menopause. The implementation of IL-1RA action is carried out in parallel with the activation of mitogen-activated kinase p38 [20]. Thus, during tissue aging both the inflammation cytokine IL-1 $\beta$, and its antagonist IL-1RA, and kinase p38 are closely interrelated and negatively control each other in a complex cellular and chemical processes.

Study objective: to study the molecular and cellular mechanisms of vaginal wall aging and the effect of the use of hormone-containing drugs for topical use.

\section{Material and Methods of Study}

Biopsies $(0.5 \mathrm{~cm} \times 1.0 \mathrm{~cm})$ from the area of the lower third of the posterior vaginal wall of women undergoing vaginoplasty were used as a material for cell culture. The appropriate informed consent was obtained from each patient. The local ethical committee approved the design of the study and other statures. In vitro aging of vaginal epithelial cell culture was simulated, which consisted in its long-term cultivation. The age of all patients was up to 35 years, the material was taken on the 20-22 day of the menstrual cycle. The effect of 4 drugs on vaginal wall cells was studied: monotherapy with estriol $0.5 \mathrm{mg}$ (Ovestin, Aspen Pharma Trading Limited, Ireland), monotherapy with micronized bioidentical progesterone 100 mg (Utrogestan, Besins Healthcare SA, Belgium), a complex preparation of estriol $0.03 \mathrm{mg}$ with lyophilized acidophilic lactobacilli at least 100 million viable Lactobacillus (Ginoflor E, Gedeon Richter, Hungary) and estriol $0.2 \mathrm{mg}$ with micronized progesterone $2 \mathrm{mg}$ and lyophilized culture of viable lactobacilli L. casei rhamnosus doderleini at least 2.107 CFU (Trioginal, Besins Healthcare SA, Belgium). For the experiment on cell cultures, all preparations produced in a capsule form were diluted in distilled water, then the solution was filtered from impurities of the related substances and introduced into the culture at each reseeding $(1.0 \mathrm{ml})$. In the control group, no drugs were administered, $1 \mathrm{ml}$ of saline was added. Cultivation was carried out up to 5 passage, which in vitro allows to simulate the aging process of cell culture. The vaginal wall sample was immediately transferred to a sterile transport medium consisting of DMEM/F-12 nutrient medium with $1 \%$ antibiotic content 1.0 $\mu \mathrm{g} / \mathrm{ml}$ penicillin $+50 \mu \mathrm{g} / \mathrm{ml}$ streptomycin) and was incubated in the refrigerator for 1-2 hours. Part of the tissue was then fixed in $10 \%$ neutral buffered formalin and sent for histological examination to confirm its histogenesis. The remaining tissue was washed from blood and secretions with Dulbecco solution without $\mathrm{Ca}$ and $\mathrm{Mg}$ ions (DPBS without $\mathrm{Ca}^{2+}$ and $\mathrm{Mg}^{2+}$ ) with the addition of $100 \mu \mathrm{l}$ of antibiotic/antimycotic [21]. The epithelium was mechanically separated from its own plate. The tissue was disintegrated with scissors and placed in a solution of $0.2 \%$ collagenase type I (Gibco, USA). Preparation of the solution was carried out taking into account the units of enzyme activity specified by the manufacturer, to a final concentration of $200 \mathrm{U} / \mathrm{min}$, with careful stirring of the contents of the test tube with the help of a laboratory vortex. After that, incubation was carried out for 30 minutes at $37 \mathrm{C}^{\circ}$ [22]. At the end of incubation, the collagenase solution was removed with a pipette. Pieces of epithelium were placed in a solution of $0.1 \%$ trypsin + EDTA (Gibco, USA). The test tube with the material was thoroughly mixed on the vortex, then the material was reincubated for 10 minutes at $37 \mathrm{C}^{\circ}$ [23]. The supernatant was carefully collected and centrifuged at $2000 \mathrm{rpm}$ for 10 minutes. Upon completion of centrifugation, trypsin+EDTA solution was removed. The isolated cells were poured over five times with 2 $\mathrm{ml}$ of a nutrient medium consisting of DMEM/F-12 (89\%), FBS $(10 \%)$ and penicillin/streptomycin +L-glutamine (1\%). At this the cells were purified from the enzyme and resuspended in $2 \mathrm{ml}$ of medium, after which they were transferred to a centrifuge tube. The resulting vaginal epithelial cell cultures at a concentration of $1 \times 1 \times 10^{3}$ cells $/ \mathrm{ml}$ were placed for 12 hours on a substrate for attachment. The number and viability of cells were evaluated using trypan blue in the Goryaev chamber. After 12 hours, the culture was washed of red blood cells and dead cells. The finished culture was maintained at $37^{\circ} \mathrm{C}$ and $5 \% \mathrm{CO}_{2}$. The culture medium changed every 2 days. Upon reaching the monolayer, the cells were detached using a mixture of $0.1 \%$ trypsin-EDTA.

The quality and identification of the obtained cell cultures were determined using a ready-made set of reagents periodic acid-Schiff reaction (PAS-reaction) (First Laboratory Company, St. Petersburg, Russia). Staining was carried out according to the instructions of the kit to identify glycoproteins, polysaccharides, some mucopolysaccharides, glycolipids and a number of fatty acids, in the resulting cultures we tracked PAS-positive carbohydratesglycogen (burgundy color) and cell nuclei (purple color). Using the immunocytochemical method, according to the standard technique, the response to 5 markers associated with cellular aging was studied: ER, PR, Ki-67, TNF $\alpha$, IL-1RA. Before this study, the cells should be attached 1-2 days to the cover glasses ( $5 \mathrm{~mm}$, Menzel) at the bottom of the wells or Petri dishes. The primary antibodies used, and their dilution are shown in Table 1.

The samples were visualized using the confocal laser scanning microscope FlueView 1000 (Olympus, Japan) at magnification $\times 400$. Lasers with wavelengths of $650 \mathrm{~nm}$ were used to verify the expression of sex steroid hormone receptors, and $405 \mathrm{~nm}$ were used to visualize cell nuclei. In the program Morphology 5.0 (Videotest, Russia), the expression area was measured. In each case, 5 visual fields were analyzed at X400 magnification. The relative expression area was calculated as the ratio of the area 
occupied by immunopositive cells to the total area of cells in the field of vision, expressed as a percentage. The results of therapeutic effects of each of the four drugs included in the study for each of the five immunocytochemical markers were compared with control responses to identical markers of the control group. The main software for statistical analysis was the IBM SPSS Statistics 22.0 statistical package. To test the hypothesis about homogeneity of the study groups at baseline, as well as after treatment, the null hypotheses (absence of differences between the groups) were tested using Student's t-test (for interval indicators with normal distribution in the study population), Mann-Whitney test (for ordinal indicators or for interval indicators with a distribution other than normal) or $\chi^{2}$ test (for qualitative characteristics). The critical level of reliability of the null statistical hypothesis was assumed to be 0.05 . In case of statistically significant differences between the groups, the magnitude of the differences between the groups was estimated.

Table 1: Primary antibodies and their dilution (immunocytochemical method).

\begin{tabular}{|c|c|c|}
\hline Antibody name & Company, country of production & Dilution \\
\hline $\begin{array}{c}\text { Estrogen Receptor alpha Monoclonal } \\
\text { Mouse Antibody (1D5) }\end{array}$ & Dako Cytomation (Denmark) & $1: 60$ \\
\hline $\begin{array}{c}\text { Progesterone Receptor Monoclonal } \\
\text { Mouse Antibody (PgR636) }\end{array}$ & Dako Cytomation (Denmark) & $1: 50$ \\
\hline $\begin{array}{c}\text { Ki-67 Monoclonal Mouse } \\
\text { Antibody (MIB-1) }\end{array}$ & Dako Cytomation (Denmark) & $1: 60$ \\
\hline $\begin{array}{c}\text { E-cadherin Monoclonal } \\
\text { Mouse Antibody }\end{array}$ & Biocare Medical (Concord, USA) \\
\hline $\begin{array}{c}\text { TNF-alpha Monoclonal } \\
\text { Mouse Antibody (68B6A3) }\end{array}$ & Diagnostic Bio Systems (Pleasanton, USA) & $1: 50$ \\
\hline
\end{tabular}

\section{Study Results}

The cytoplasm of the multilayer flat epithelium of the vagina must necessarily contain glycogen, by the presence of which with the help of PAS-reaction can be judged about the purity of the isolated cells in culture. Despite the fact that in the present experiment, none of the protocols gave pure populations of epithelial cells (there was an admixture of fibroblast/myofibroblast cells, no more than $15 \%$ ), yet the resulting cell cultures contained glycogen by $70-90 \%$, therefore, mainly consisted of cells of multilayer flat epithelium. Based on immunocytochemical studies, we were able to assess the expression of vaginal epithelial markers during cell culture aging (Figure 1). The extremely low expression of estrogen receptors in the studied samples of cell cultures was an expected response. Interestingly, despite the low expression of progesterone receptor, the area of luminescence of these proteins was still 2 times larger than ER. Along with a decrease in reception to sex steroids, the expression level of the proliferation marker Ki67 was naturally low. However, contrary to expectations, the glow of this protein in the immunocytochemical study still occupied about $14-15 \%$ of the area of the field of vision, which is 5 times more than the glow of estrogen receptors and 2 times more than the glow of progesterone receptors. Apparently, deviations of this marker of cell proliferation, well-proven in the diagnosis of genital tumors, endometriosis and breast cancer, in GUMS are not sufficiently indicative. Most likely, Ki-67 should not be used for diagnostic or scientific purposes in works devoted to the natural changes of the vaginal wall in peri - and postmenopausal conditions. At the same time, such a marker of cellular aging as TNFa in the studied cell cultures showed a fairly high expression, which reached almost the fifth part of the area of the fields of vision. But the most labile (and, apparently, sensitive) marker of GUMS in cells was an antagonist of interleukin-1. The level of IL1RA expression in the studied cell cultures reached $21.4 \pm 8.1 \%$ of the visual fields. Despite the above interesting observations, the biochemical pattern of vaginal wall cells in vulvovaginal atrophy (GUMS) can not be complete in the absence of clear reference values of the selected markers for normal vaginal cells, even if they have undergone age-related changes. To understand the processes occurring at the biochemical and cellular levels in the vaginal wall in GUMS, it is impossible to do without analyzing the changes in these same cell markers after therapy with mono - and complex drugs estriol, micronized progesterone and Lactobacillus culture in various combinations. Ideally, as a result of such an analysis, it is possible to obtain justifications for choosing the optimal therapeutic effect.

In vitro on cell culture we carried out modeling of aging processes occurring in the vaginal wall in women in peri - and postmenopausal women. Additionally, we incubated the vaginal epithelium for a long time - with cell division of the culture we brought it to the $5^{\text {th }}$ passage, with the maximum possible cultivation according to the literature - to the $6^{\text {th }}$ passage, thus the aging of the cell culture was simulated. The drugs were administered at each reseeding and their impact on the culture was assessed. After 
the $5^{\text {th }}$ passage in all cultures, except those in which the monopreparation estriol was administered, an increase in the average maximum value of the relative response area with the marker to estrogen receptors was achieved. This response, as it should be, was detected in the cell nuclei of vaginal wall cells, where ER expression was significantly $(\mathrm{p}<0.05)$ increased by almost 2 times after exposure to a complex drug estriol $0.2 \mathrm{mg}$ with micronized progesterone $2 \mathrm{mg}$ and lyophilized culture of viable lactobacilli $L$. casei rhamnosus Doderleini at least 2*107 CFU (Figure 2, Table 2).

Table 2: The expression of ER in cell culture of the vaginal wall (immunocytochemical method).

\begin{tabular}{|c|c|c|c|}
\hline Groups & Prior to exposure & After exposure & $\mathbf{p}$ \\
\hline $\begin{array}{c}\text { I. Estriol } 0.2 \mathrm{mg}+\text { micronized progesterone } \\
2 \mathrm{mg}+\text { L. casei rhamnosus Doderleini at least } 2 \cdot 107 \mathrm{CFU}\end{array}$ & \multirow{4}{*}{$3.3 \pm 1.2$} & $5.8 \pm 2.2$ & $<0.05$ \\
\hline $\begin{array}{l}\text { II. Estriol } 0.03 \mathrm{mg}+\text { acidophilic } \\
\text { Lactobacillus lyophilisate at least } 100 \text { million viable Lactobacillus }\end{array}$ & & $3.8 \pm 0.9$ & $>0.05$ \\
\hline III. Estriol $0.5 \mathrm{mg}$ & & $3.2 \pm 0.6$ & $>0.05$ \\
\hline IV. Progesterone 100 mg & & $4.3 \pm 2.1$ & $>0.05$ \\
\hline
\end{tabular}

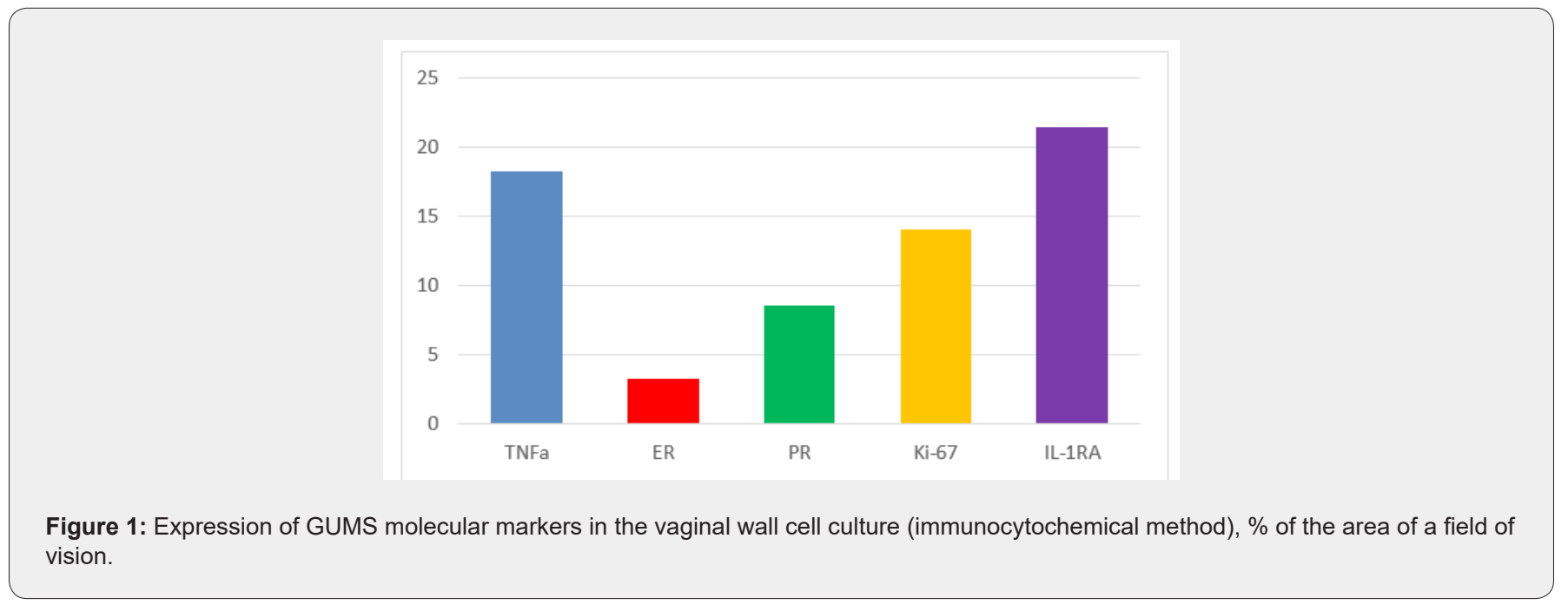

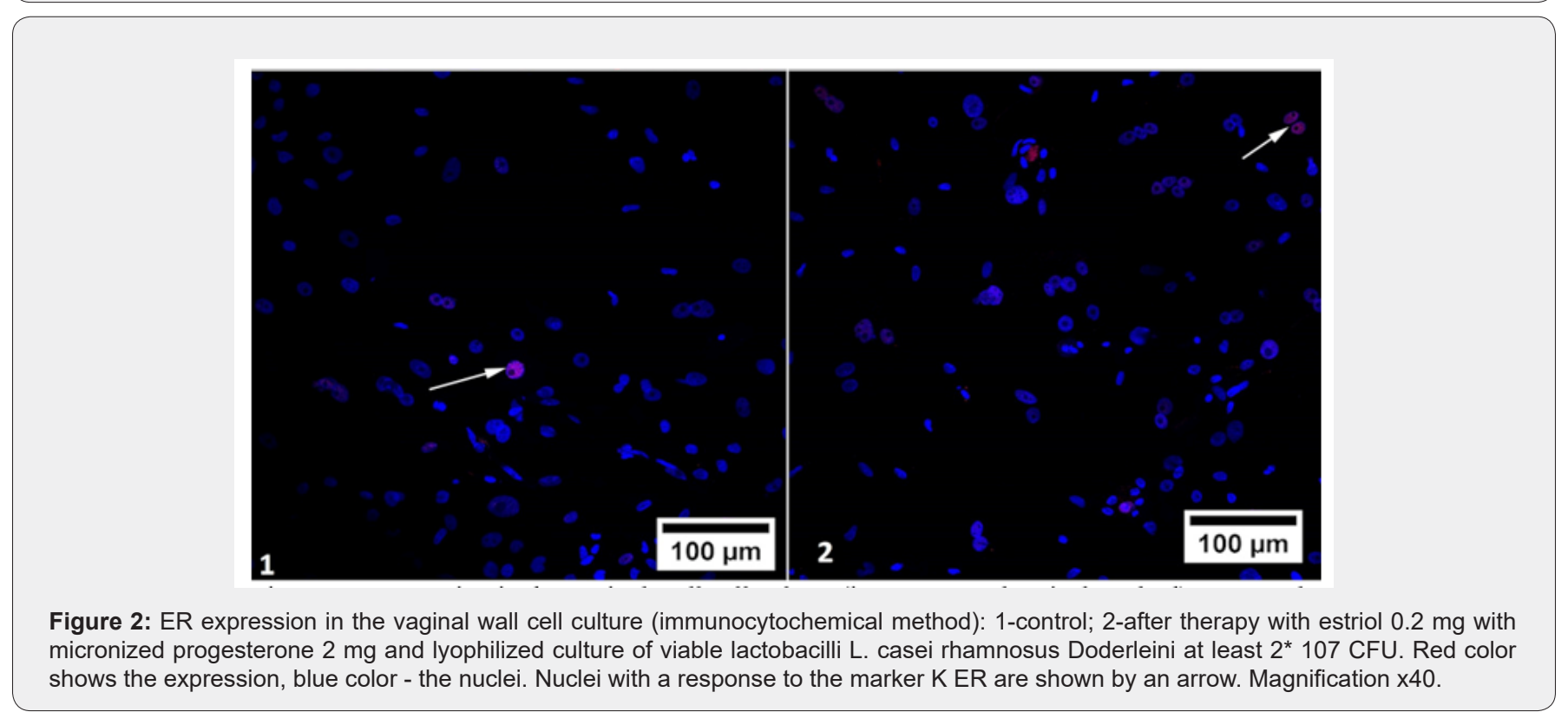


An important and interesting observation was a paradoxical, though statistically unreliable, decrease in the area of ER luminescence after a course of therapy with estriol mono-preparation. The addition of a probiotic to estriol statistically unreliable slightly increased this value, leveling the inhibitory effect of estriol for ER expression in cell cultures obtained from vaginal biopsies of women. When studying the immunocytochemical response with the marker K ER after exposure to micronized progesterone mono-preparation, large average values of ER expression in cell culture were shown in comparison with the preparations of estriol and estriol+probiotic in this experiment. However, in this case, there was also no statistically significant difference when comparing prior to and after exposure to progesterone mono-preparation). It is possible that it is progesterone, not estrogen, that stimulates the synthesis of estrogen reception in the nuclei of hormone-dependent cells. The average ER expression area of micronized progesterone mono-preparation increased by 1.3 times ( $p>0.05)$. Statistically significant difference in ER expression was obtained when applying to the studied cultures of the drug estriol $0.2 \mathrm{mg}$ with micronized progesterone $2 \mathrm{mg}$ and lyophilized culture of viable lactobacilli L. casei rhamnosus Doderleini at least $2 * 107 \mathrm{CFU}$ in comparison with its expression in control cultures and cultures that were exposed to other substances.

The response with the marker to progesterone receptors was also detected in cell nuclei (Figure 3), which confirms the technical correctness of the study. The effect of drugs on the severity of the immunocytochemical response of PR proteins was different (Table 3). As in the evaluation of ER expression, in the group of Estriol $0.2 \mathrm{mg}+$ micronized progesterone $2 \mathrm{mg}+$ L. casei rhamnosus Doderleini not less than $2 * 107$ CFU, it was found that in the nuclei of cell cultures produced from the vaginal walls, the area of PR luminescence significantly increased compared to its expression in control cultures and cultures that were exposed to other substances $(\mathrm{p}<0.05)$, Figure 3 . We drew attention to the fact that the drugs Estriol $0.5 \mathrm{mg}$ and Estriol $0.03 \mathrm{mg}+$ lyophilizate acidophilic lactobacilli at least 100 million viable Lactobacillus almost did not change the expression of progesterone receptors. At the same time, the expression of PR remained approximately at the same level after exposure of the cell culture to these drugs (the differences are not statistically significant).

Table 3: PR expression in vaginal wall cell culture (immunocytochemical method).

\begin{tabular}{|c|c|c|c|}
\hline Groups & Prior to exposure & After exposure & $\mathbf{p}$ \\
\hline $\begin{array}{c}\text { I. Estriol } 0.2 \mathrm{mg}+\text { micronized progesterone } \\
2 \mathrm{mg}+\text { L. casei rhamnosus Doderleini at least } 2 \cdot 107 \mathrm{CFU}\end{array}$ & \multirow{4}{*}{$8.5 \pm 3.3$} & $9.8 \pm 2.9$ & $<0.05$ \\
\hline $\begin{array}{l}\text { II. Estriol } 0.03 \mathrm{mg}+\text { acidophilic } \\
\text { Lactobacillus lyophilisate at least } 100 \text { million viable Lactobacillus }\end{array}$ & & $8.6 \pm 2.6$ & $>0.05$ \\
\hline III. Estriol $0.5 \mathrm{mg}$ & & $8.2 \pm 3.5$ & $>0.05$ \\
\hline IV. Progesterone $100 \mathrm{mg}$ & & $6.7 \pm 1.4$ & $<0.05$ \\
\hline
\end{tabular}

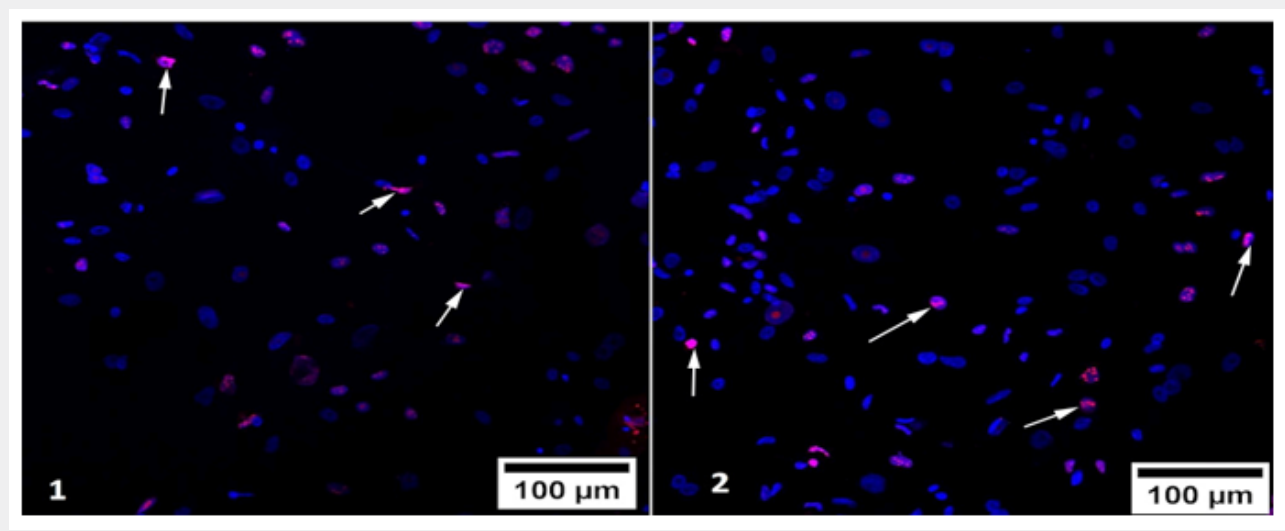

Figure 3: Progesterone receptor expression in vaginal wall cell culture (immunocytochemical method): 1 - control; 2 - culture with the preparation of estriol $0.2 \mathrm{mg}$ with micronized progesterone $2 \mathrm{mg}$ and lyophilized culture of viable lactobacilli L. casei rhamnosus Doderleini at least $2 * 107$ CFU. Red color shows the expression, blue color - the nuclei. Nuclei with a response to the marker to PR are shown by an arrow. Magnification $\times 40$.

Another surprise was the statistically significant decrease in PR expression in culture with micronized progesterone monopreparation. The area of positive immunocytochemical response with PR marker decreased in comparison with control cell culture by 1.3 times $(\mathrm{p}<0.05)$. This means that monoprogesterone exposure negatively affects the development of auto reception 
in patients in peri - and postmenopause, which once again confirms the polyhormonal concept of the pathogenesis of vulvo-vaginal atrophy. The effect of sex steroids on vaginal cells should intensify their proliferative activity, and thus increase the expression of biochemical proliferation markers. We studied the immunocytochemical response to one of them - to the protein Ki67 (Table 4). As can be seen from table 4, none of the drugs was able to statistically significantly change the proportion of the area of illumination to the total area of the fields of vision ( $p>0.05$ ). This does not mean that hormonal drugs for topical therapy of GUMS do not have the proliferative effects: the level of Ki-67 expression in the studied vaginal wall cell cultures increased by 1.2 times after exposure to estriol mono-preparation and 1.3 times after exposure to a complex drug, where estriol was combined with progesterone and Lactobacillus culture. The conclusion is obvious: lactobacilli as the main component of the vaginal biotope, apparently, can control estrogen-dependent proliferation of epithelial cells. This fact is surprising in itself, because it is known that the substrate for the vital activity of lactobacilli in the vagina is glycogen, the amount of which directly depends on the intensity of proliferation of the multilayer flat non-keratinizing epithelium.

Table 4: The expression of Ki-67 in cell culture of the vaginal wall (immunocytochemical method).

\begin{tabular}{|c|c|c|c|}
\hline Groups & Prior to exposure & After exposure & $\mathbf{p}$ \\
\hline $\begin{array}{c}\text { I. Estriol } 0.2 \mathrm{mg}+\text { micronized progesterone } \\
2 \mathrm{mg}+\text { L. casei rhamnosus Doderleini at least } 2 \cdot 107 \mathrm{CFU}\end{array}$ & \multirow{4}{*}{$14.0 \pm 4.6$} & $17.8 \pm 5.8$ & $>0.05$ \\
\hline $\begin{array}{l}\text { II. Estriol } 0.03 \mathrm{mg}+\text { acidophilic } \\
\text { Lactobacillus lyophilisate at least } 100 \text { million viable Lactobacillus }\end{array}$ & & $15.3 \pm 6.3$ & $>0.05$ \\
\hline III. Estriol $0.5 \mathrm{mg}$ & & $16.2 \pm 5.7$ & $>0.05$ \\
\hline IV. Progesterone $100 \mathrm{mg}$ & & $13.5 \pm 5.3$ & $>0.05$ \\
\hline
\end{tabular}

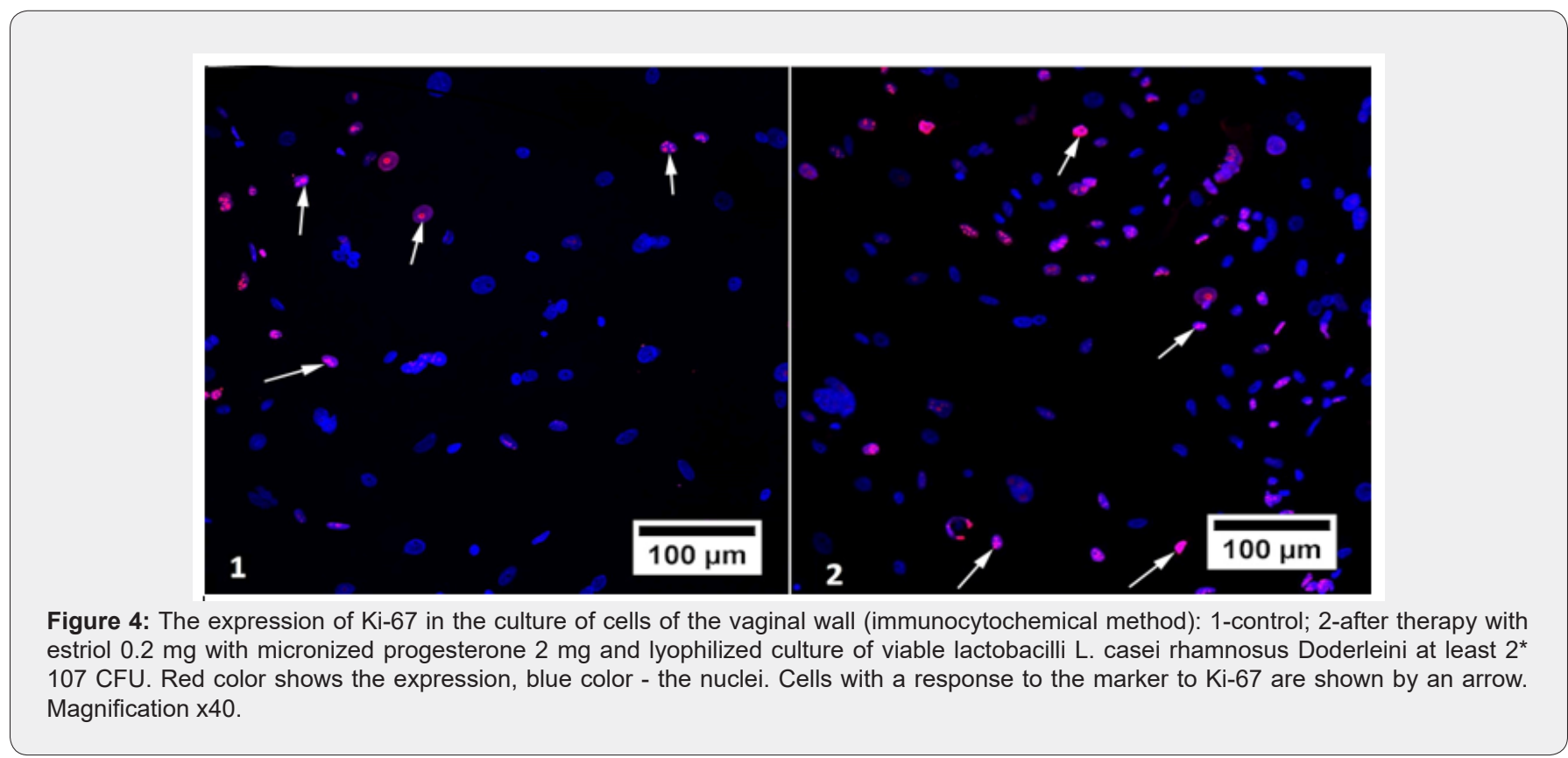

The absence of the effect of micronized progesterone monopreparation on the level of Ki-67 proliferation marker in the studied cell cultures (its expression was statistically reduced) was not a discovery, since the antiproliferative effect of gestagens in conditions of estrogen deprivation is known and widely used in the treatment of hyperplastic processes in estrogen-dependent tissues (for example, endometrial hyperplasia, endometriosis, benign breast dysplasia, etc.). But in the case of progesterone exposure to tissues together with estrogens, these sex steroids potentiate the action of each other - hence the most pronounced, although statistically unreliable, immunocytochemical response, which was exerted on the vaginal epithelial cells by a complex preparation of estriol, progesterone and lactobacilli (Figure 4). Another conclusion that we were forced to make, after analyzing the proliferative activity in cultures of vaginal wall cells, was the obvious inexpediency of using the marker of proliferation Ki-67 
neither for research works on GUMS, nor for the diagnosis of this condition in practical medicine, since in the studied samples there were no statistically significant differences between the groups. Apparently, for these purposes, one should look for other, more sensitive markers.

The response with an immunocytochemical marker to a protein reflecting the processes of cellular aging $\mathrm{TNF} \alpha$ was expressed in the cell membrane, the average values of the relative area of expression of this protein before and after exposure to hormonecontaining drugs are indicated in table 5. It was found that the effect of hormone-containing mono-preparations of estriol and micronized progesterone, as well as the complex preparation of estriol with probiotic statistically unreliable increased the relative area of the fluorescence of TNF $\alpha(\mathrm{p}>0.05)$. The incorporation of three components (Estriol + micronized progesterone + probiotic) into the preparation reduced the expression of the used marker of cellular aging in comparison with its expression in control cultures and cultures that were exposed to other substances $(\mathrm{p}<0.05)$. And if the use of lactobacilli in combination with estriol as the only hormonal component in the composition of estriol $0.03 \mathrm{mg}+$ lyophilizate acidophilic lactobacilli at least 100 million viable Lactobacillus reduced TNF $\alpha$ expression slightly and statistically unreliable ( $p>0.05)$, the addition of progesterone to this composition led to more convincing results: fluorescence area after therapy with estriol $0.2 \mathrm{mg}+$ micronized progesterone $2 \mathrm{mg}$ + L. casei rhamnosus Doderleini at least $2 * 107$ CFU significantly decreased by 1.3 times $(\mathrm{p}<0.05)$, Figure 5 . Finally, we investigated the immunocytochemical response to an anti-inflammatory agent such as IL-1RA, i.e. an antagonist of receptors to interleukin-1 (Table 6).

Table 5: The expression of TNFa in cell culture of the vaginal wall (immunocytochemical method).

\begin{tabular}{|c|c|c|}
\hline Groups & Prior to exposure & After exposure \\
\hline $\begin{array}{c}\text { I. Estriol } 0.2 \mathrm{mg}+\text { micronized } \\
\text { progesterone } 2 \mathrm{mg}+\mathrm{L} .\end{array}$ & & $14.5 \pm 2.9$ \\
\hline $\begin{array}{c}\text { casei rhamnosus Doderleini at least } 2 \cdot 107 \mathrm{CFU} \\
\text { II. Estriol } 0.03 \mathrm{mg}+\text { acidophilic } \\
\text { Lactobacillus lyophilisate } \\
\text { at least } 100 \text { million viable Lactobacillus }\end{array}$ & \multirow{2}{*}{$18.2 \pm 4.5$} & $16.8 \pm 3.4$ \\
\hline III. Estriol $0.5 \mathrm{mg}$ & & $>0.05$ \\
\hline IV. Progesterone $100 \mathrm{mg}$ & & $>0.05$ \\
\hline
\end{tabular}

Table 6: Expression of IL-1RA in vaginal wall cell culture (immunocytochemical method).

\begin{tabular}{|c|c|c|c|}
\hline Groups & Prior to exposure & After exposure & $\mathbf{p}$ \\
\hline $\begin{array}{l}\text { I. Estriol } 0.2 \mathrm{mg}+\text { micronized } \\
\text { progesterone } 2 \mathrm{mg}+\text { L. casei rhamnosus Doderleini at least } 2 \cdot 107 \mathrm{CFU}\end{array}$ & \multirow{4}{*}{$21.4 \pm 8.1$} & $11.8 \pm 4.1$ & $<0.05$ \\
\hline $\begin{array}{l}\text { II. Estriol } 0.03 \mathrm{mg}+\text { acidophilic } \\
\text { Lactobacillus lyophilisate at least } 100 \text { million viable Lactobacillus }\end{array}$ & & $16.4 \pm 3.4$ & $<0.05$ \\
\hline III. Estriol $0.5 \mathrm{mg}$ & & $17.4 \pm 4.4$ & $<0.05$ \\
\hline IV. Progesterone 100 mg & & $16.3 \pm 1.3$ & $<0.05$ \\
\hline
\end{tabular}




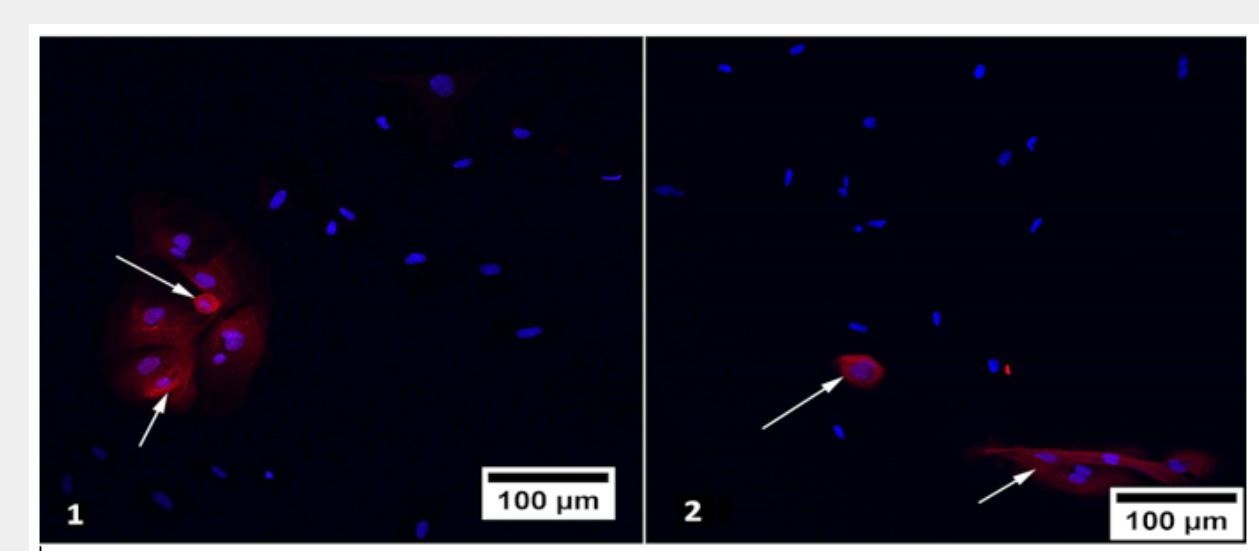

Figure 5: The expression of TNFa in the cell culture walls (immunocytochemical method): 1-control; 2-after therapy with estriol $0.2 \mathrm{mg}$ with micronized progesterone $2 \mathrm{mg}$ and lyophilized culture of viable lactobacilli L. casei rhamnosus Doderleini at least 2* $107 \mathrm{CFU}$. Red color shows the expression, blue color - the nuclei. Cells with a response to the TNFa marker are shown by an arrow. Magnification x40.

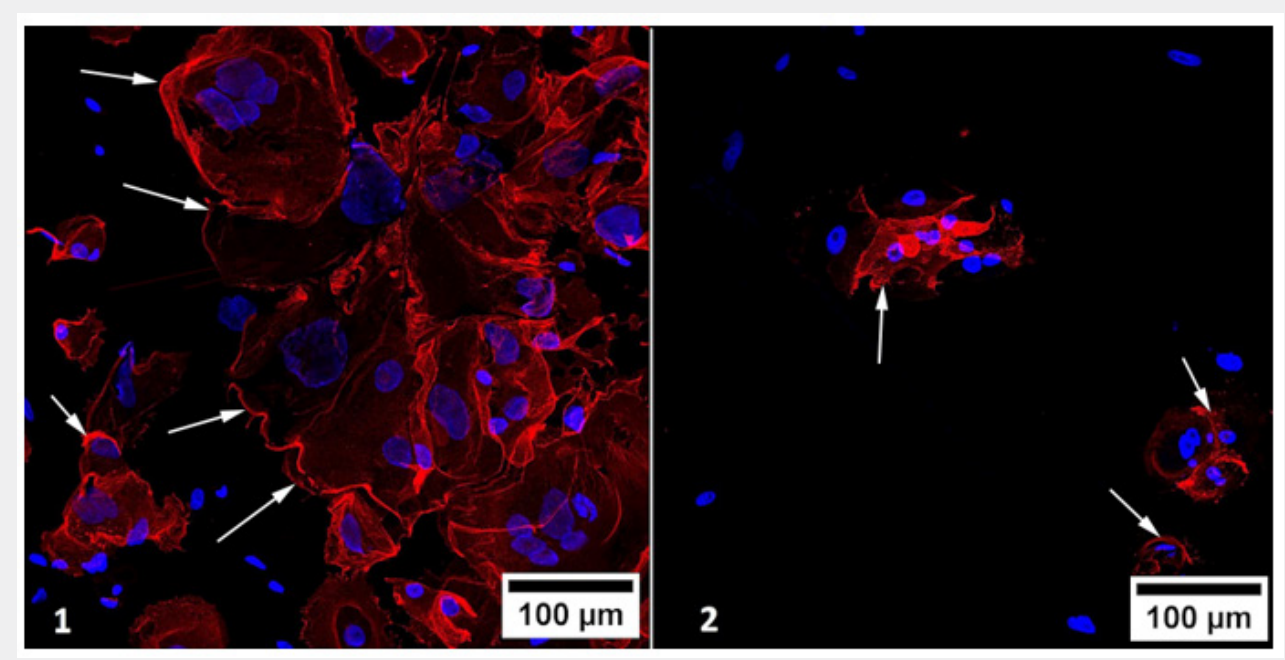

Figure 6: Expression of IL-1RA in vaginal wall cell culture (immunocytochemical method): 1-control; 2-after therapy with estriol $0.2 \mathrm{mg}$ with micronized progesterone $2 \mathrm{mg}$ and lyophilized culture of viable lactobacilli L. casei rhamnosus Doderleini at least 2* $107 \mathrm{CFU}$. Red color shows the expression, blue color - the nuclei. Cells with a response to the marker to IL-1RA are shown by an arrow. Magnification x40.

The immunocytochemical method showed a significant decrease in the expression of IL-1RA after the use of each of the drugs examined in the study, in comparison with the control study of cell cultures of the vaginal wall. Minimal changes in the expression of IL-1RA were found after exposure to estriol in combination with probiotic - it decreased by 1.2 times $(\mathrm{p}<0.05)$, but the mono-preparation of estriol reduced the response area with this marker by 1.3 times $(\mathrm{p}<0.05)$, and the complex preparation of estriol micronized progesterone and probiotic by almost 2 times $(\mathrm{p}<0.05)$. It turns out that in eubiotic conditions, anti-inflammatory processes develop more intensely, and the probiotic counteracts estriol-dependent proliferation of vaginal wall cells (presumably, controls excessive proliferation), and in the presence of progesterone, the inflammatory component is leveled significantly more. Interestingly, the mono-preparation of micronized progesterone has a more pronounced effect on the expression of IL-1RA than estrogen, reducing the response area with the marker by 1.4 times ( $\mathrm{p}<0.05)$, exerting an antiaging effect on target cells. But the most pronounced suppressive effect on the expression of IL-1RA was achieved with the help of complex effects of estriol, progesterone and lactobacilli, which reduced the severity of the immunocytochemical response by 1.8 times compared to its expression in control cultures and cultures that were exposed to other substances $(\mathrm{p}<0.05)$, Figure 6 . As in the study of other markers, the mutually potentiating effect of the three components significantly improves the biochemical functioning of the vaginal wall cells, which was not achieved by mono-preparations of sex steroids. 


\section{Discussion}

In the reproductive period of a woman's life, with a sufficient level of estrogen, and last but not least, progesterone effects on the tissues, the proliferation of vaginal cells is stimulated. The multilayer flat non-keratinizing (squamous) epithelium of the vaginal wall is known to be a glycogen-producing and constantly exfoliating tissue. Glycogen production is directly dependent on estrogen proliferative influence. But our study showed that estrogen mono-exposure on vaginal cells inhibits the expression in their nuclei of both estrogen and progesterone receptors. Progesterone has a stimulating effect on estrogen receptor expression. Thus, it is progesterone that creates the conditions for the estrogenization of vaginal cells, and hence the glycogen synthesis. Healthy vaginal flora consists of a wide variety of aerobic and anaerobic, gram-positive and gram-negative bacteria and other commensals, most of which are represented by lactobacilli. The result of lactic acid fermentation of glycogen is the presence of lactic acid and hydrogen peroxide in the vaginal discharge. The antiseptic properties of hydrogen peroxide are known, and lactic acid provides a vagina-specific acidic environment of the biotope $\mathrm{pH} 3.8-4.5$, thanks to which most opportunistic vaginal flora cannot effectively reproduce and cause inflammation of this inherently infected area. An important finding of our study was the detection of the dependence of the growth of estrogen receptors not only on progesterone, but also on the degree of lactobacilli colonization. Apparently, for the formation of estrogen receptors, only progesterone exposure is not enough, and a certain, low, $\mathrm{pH}$ level is necessary. Suppose that this acidic environment contributes to the expression of progesterone reception.

Thus, the normal anatomical and functional state of the vagina, its homeostasis is provided by the close interaction of the hormone-dependent vaginal epithelium and its bacterial microbiocenosis. This shows the vicious circle of pathogenesis of GUMS: decreased progesterone exposure $\rightarrow$ decreased estrogen reception $\rightarrow$ decreased proliferation $\rightarrow$ decreased glycogen $\rightarrow$ increased $\mathrm{pH} \rightarrow$ decreased progesterone reception $\rightarrow$ decreased progesterone exposure. we investigated the protein Ki-67, wellproven in hyperplastic processes of reproductive system target organs, as a marker of cell proliferation, but its changes after treatment, despite the achieved increase in the reception to sex steroids, did not show significant statistical differences. This does not indicate a lack of proliferative activity in the cell cultures studied, but rather that markers of excess cell proliferation cannot be accepted for the analysis of proliferation in atrophied or hypotrophic non-tumor tissues. Apparently, the search for suitable markers of cell non-tumor proliferation for these conditions is a necessary task for every researcher trying to understand the molecular cellular mechanisms of GUMS. As a result of changes in the level of sex steroids, and then the reception to them, there are changes in the cellular composition-the disappearance of surface and intermediate cells of the multilayer squamous epithelium: the intake of glycogen into the vagina in the composition of desquamated epithelial cells is disrupted, the pool of lactobacilli in the vaginal biotope decreases, the $\mathrm{pH}$ of the medium increases, conditions are created for the activation of opportunistic flora and, as a consequence, for inflammatory and dysbiotic processes [24]. It is important to understand that this inflammatory process does not occur on proliferatively altered tissues with exudative potential, but atypically-on atrophic, thinned, poorly bloodsupplied epithelium. I.e. the described processes lead to cellular aging of cells.

One of the markers of cellular aging, whose expression increases as hormonal and eubiotic effects decrease, is TNF $\alpha$. But the most significant in our work were changes in the synthesis of anti-inflammatory receptor antagonist to interleukin-1, IL-1RA [25]. The increase in its expression, most likely, is a reflection of a special, atypical current vaginitis in GUMS, as mentioned above. It is important that the severity of the immunocytochemical response to the TNF $\alpha$ marker was best affected by drugs containing a probiotic. And the intensity of production of IL1RA lactobacilli, is rather restrained (or, to be more precise, had a controlling effect). It can be suggested that IL-1RA is triggered by the development of senile (atrophic) vaginitis, suppressing the pro-inflammatory effect of IL-1, protecting thinning vaginal tissues from destruction and therefore working as a marker of cellular aging. After analyzing the effect of four hormone-containing drugs for vaginal administration, it was impossible not to note that the only marker that showed significant changes in expression when exposed to any of these agents was IL-1RA. And the only tool that showed significant improvements in all studied biochemical markers, except Ki-67, was a complex preparation of estriol 0.2 $\mathrm{mg}$ with micronized progesterone $2 \mathrm{mg}$ and lyophilized culture of viable lactobacilli L. casei rhamnosus Doderleini at least $2 * 10^{7} \mathrm{CFU}$. When comparing this drug with other drugs, it seems obvious to us that its advantage is a balanced, pathogenetically justified composition that allows acting simultaneously on estrogen and progesterone receptors, and on the $\mathrm{pH}$ level directly, thereby effectively achieving normalization of the morpho functional state of the vagina.

\section{Conclusion}

Studies suggest that drugs for topical therapy of genitourinary menopausal syndrome can have a therapeutic effect on vaginal wall cells through the regulation of the expression of signaling molecules (biomarkers). Pathogenetically justified therapy of GUMS is not only therapy with estriol, but a combination therapy with progesterone and lactobacilli. It was the complex preparation of estriol $0.2 \mathrm{mg}$ with micronized progesterone $2 \mathrm{mg}$ and lyophilized culture of viable lactobacilli L. casei rhamnosus Doderleini at least $2 * 10^{7} \mathrm{CFU}$ that showed a statistically significant increase in the expression of progesterone and estrogen receptors, as well as a significant decrease in the immunocytochemical response to the marker of cellular aging $\mathrm{TNF} \alpha$, which was not achieved using nonhormonal drugs. 


\section{References}

1. Portman DJ, Gass ML Vulvovaginal atrophy terminology consensus conference panel (2014) Genitourinary syndrome of menopause: new terminology for vulvovaginal atrophy from the international society for the study of women's sexual health and the North American Menopause Society. Menopause 21(10): 1063-1068.

2. Ezdakov JM, Gimaev IA, Tihonov DA (2017) A review of current ideas about the structure and function of estrogen receptors, their conformational changes when interacting with agonists and antagonists. Universum: Himija i biologija: jelektronnyj nauchnyj zhurnal 9:(39).

3. Zerbinati N, Serati M, Origoni M, Candiani M, Iannitti T, et al. (2015) Microscopic and ultrastructural modifications of postmenopausal atrophic vaginal mucosa after fractional carbon dioxide laser treatment. Lasers Med Sci 30(1): 429-436.

4. Marron MB, Hughes DP, McCarthy MJ, Beaumont ER, Brindle NP (2000) Tie-1 receptor tyrosine kinase endodomain interaction with SHP2: potential signalling mechanisms and roles in angiogenesis. Adv Exp Med Biol 476: 35-46.

5. Mehta FF, Son J, Hewitt SC, Jang E, Lydon JP, et al. (2016) Distinct functions and regulation of epithelial progesterone receptor in the mouse cervix, vagina, and uterus. Oncotarget 7(14): 17455-17467.

6. Vorobyova VO, Novichkov EV (2015) Receptors for progesterone in the cells of malignant endometrioid ovarian tumors and disease prognosis. Scientific articles 47: 23-27.

7. Murdock TA, Veras EFT, Kurman RJ, Mazur MT (2019) Effects of Hormones. In: Diagnosis of Endometrial Biopsies and Curettings. Springer, Cham.

8. Li LT, Jiang G, Chen Q Zheng JN (2014) Ki67 is a promising molecular target in the diagnosis of cancer (Review). Mol Med Rep 1566-1572.

9. Sun X, Kaufman PD (2018) Ki-67: more than a proliferation marker. Chromosoma. 127(2): 175-186.

10. Grigorian IJu, Polyakova VO, Linkova NS, Kukanova EO, Paltseva EM (2015) Age-related features of the signal molecules profile in endometrium: perspectives for diagnosis of gynecological pathology. Molecular medicine 3: 48-52.

11. Sobecki M, Mrouj K, Camasses A, Parisis N, Nicolas E, et al. (2016) The cell proliferation antigen Ki-67 organises heterochromatin. Elife 5: e13722.

12. Scholzen T, Gerdes J (2000) The Ki-67 protein: from the known and the unknown. J Cell Physiol 182(3): 311-322.

13. Ciebiera M, Włodarczyk M, Zgliczyńska M, Łukaszuk K, Męczekalski B, et al. (2018) The role of tumor necrosis factor $\alpha$ in the biology of uterine fibroids and the related symptoms. Int J Mol Sci 19(12): 3869.
14. Burmenskaya OV, Bayramova GR, Nepsha OS, Donnikov AE (2011) Cytokine profile of immunocompetent vaginal cells in chronic recurrent vulvovaginal candidosis. Obstetrics and Gynecology 3 (81):44-49.

15. Miyazaki K, Hashimoto K, Sato M, Watanabe M, Tomikawa N, et al. (2017) Establishment of a method for evaluating endothelial cell injury by TNF- $\alpha$ in vitro for clarifying the pathophysiology of virus-associated acute encephalopathy. Pediatr Res 81(6): 942-947.

16. Lipatov IS, YuV Tezikov, Martynova NV, Protasov AD, Bukreeva AA (2016) Content of angiogenic factors, markers of apoptosis and proliferation in newborns from mothers with placental ovarian stimulation syndrome. Modern Problems of Science and Education 5: 34-28.

17. Dayer JM, Oliviero F, Punzi L (2017) A brief history of IL-1 and IL-1RA in rheumatology. Front. Pharmacol.

18. Hearps AC, Tyssen D, Srbinovski D, Bayigga L, Diaz DJD, etal.Vaginal lactic acid elicits an anti-inflammatory response from human cervicovaginal epithelial cells and inhibits production of pro-inflammatory mediators associated with HIV acquisition. Mucosal Immunol 10(6): 1480-1490.

19. Dinarello CA (2018) Overview of the IL-1 family in innate inflammation and acquired immunity. Immunol Rev 281(1): 8-27.

20. Hedl M, Abraham C (2011) Distinct roles for Nod2 protein and autocrine interleukin-1 $\beta$ in muramyl dipeptide-induced mitogenactivated protein kinase activation and cytokine secretion in human macrophages. J Biol Chem 286(30): 26440-26449.

21. Herbst-Kralovetz MM, Quayle AJ, Ficarra M, Greene S, Rose WA, et al. (2008) Quantification and comparison of toll-like receptor expression and responsiveness in primary and immortalized human female lower genital tract epithelia. Am J Reprod Immunol 59(3): 212-224.

22. Iguchi T, Uchima FD, Ostrander PL, Bern HA (1983) Growth of normal mouse vaginal epithelial cells in and on collagen gels. Proc Natl Acad Sci U S A 80(12): 3743-3747.

23. Sarmento B (2015) Concepts and Models for Drug Permeability Studies 408: $275-281$.

24. García-Gómez E, González-Pedrajo B, Camacho-Arroyo I (2013) Role of sex steroid hormones in bacterial-host interactions. Biomed Res Int 2013: 928290.

25. Hearps AC, Tyssen D, Srbinovski D, Bayigga L, Diaz DJD, et al. (2017) Vaginal lactic acid elicits an anti-inflammatory response from human cervicovaginal epithelial cells and inhibits production of proinflammatory mediators associated with HIV acquisition. Mucosal Immunol 10(6): 1480-1490. 


\section{Your next submission with Juniper Publishers will reach you the below assets}

- Quality Editorial service

- Swift Peer Review

- Reprints availability

- E-prints Service

- Manuscript Podcast for convenient understanding

- Global attainment for your research

- Manuscript accessibility in different formats

( Pdf, E-pub, Full Tsext, Audio)

- Unceasing customer service

Track the below URL for one-step submission

https://juniperpublishers.com/online-submission.php 